\section{Reaction of the Ambident Electrophile Dimethyl Carbonate with the Ambident Nucleophile Phenylhydrazine}

\author{
Anthony E. Rosamilia, ${ }^{\dagger}$ Fabio Aricò ${ }^{\dagger}$ and Pietro Tundo*,†, \\ Consorzio Interuniversitario Nazionale La Chimica per \\ l'Ambiente (INCA), 21/8 Via delle Industrie, Marghera (VE), \\ 30175, Italy, and Dipartimento di Scienze Ambientali, \\ Università Ca' Foscari Venezia, 2137 Dorsoduro (VE),
} 30123, Italy

tundop@unive.it

Received August 31, 2007

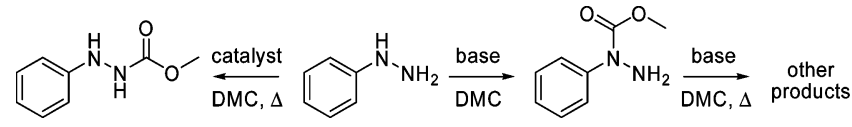

To explore the ambident electrophilic reactivity of dimethyl carbonate (DMC), reactions with the ambident nucleophile phenylhydrazine were investigated. When a Brönsted base was used, selective carboxymethylation occurred at $\mathrm{N}-1$, after that several other compounds were produced selectively utilizing various conditions. Formation of these compounds was explained by using the Hard-Soft Acid-Base (HSAB) theory. Catalysis by some metal salts altered the reactivity of phenylhydrazine, which effected selective carboxymethylation at N-2 of phenylhydrazine instead.

Dimethyl carbonate (DMC) is a well-known nontoxic reagent and solvent that has been used for many Green applications, namely the substitution of toxic reagents such as methyl halides and phosgene for the selective methylation and carboxymethylation, respectively, of numerous nucleophiles. ${ }^{1}$ Both transformations are possible owing to the two nonequivalent electrophilic centers of DMC, making it an ambident electrophile. Selectivity toward either center can be attributed to the HardSoft Acid-Base (HSAB) theory, introduced by Pearson. ${ }^{2}$ In the context of DMC, the theory can be simply applied by suggesting DMC will carboxymethylate (hard reaction) hard nucleophiles or methylate (soft reaction) soft nucleophiles. It should be pointed out that this classification is a relative assignment for the differing reactivities of the two electrophilic centers of DMC.

A prime example that demonstrates both hard and soft nucleophilicity in a tandem reaction, and is also relevant to this report, is the reaction of arylacetonitriles with DMC. ${ }^{3}$ From the

* Author to whom correspondence should be addressed.

† Consorzio Interuniversitario Nazionale La Chimica per l'Ambiente (INCA).

¥ Università Ca’ Foscari Venezia.

(1) Tundo, P.; Selva, M. Acc. Chem. Res. 2002, 35, 706-716. Selva, M.; Tundo, P. J. Org. Chem. 2006, 71, 1464-1470. Shieh, W.-C.; Dell, S.; Bach, A.; Repic, O.; Blacklock, T. J. J. Org. Chem. 2003, 68, 19541957.

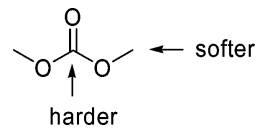

starting material, e.g., phenylacetonitrile, an anion is generated with a Brönsted base; the anion is a hard nucleophile and thus reacts with DMC to produce the carboxymethylated arylacetonitrile 2. Bearing the carboxylate group, the reactive carbon anion is rendered a soft nucleophilic center and undergoes methylation to produce the methyl carboxymethylated arylacetonitrile 3. Reaction between $\mathrm{MeOH}$ and $\mathbf{3}$ results in the formation of 2-methyl-2-phenylacetonitrile (4), which does not readily undergo methylation because the loss of the carboxymethyl moiety renders the carbon a hard nucleophilic center, which only permits the carboxymethylation to reproduce $\mathbf{3}$. Significantly, the reaction was carried out with DMC as a solvent/reagent; after complete conversion the selectivity for the mono-methylated product 4 was $>99 \%$.

DMC has also been shown to react analogously with other nucleophiles, such as amino compounds. ${ }^{4}$ In an effort to explore this concept further, a more complex class of nucleophile was sought. In particular, ambident nucleophiles were of interest due to the appealing concept of exploring reactions of ambident nucleophiles with ambident electrophiles.

Phenylhydrazine was our first choice for an ambident nucleophile. On face value, it is a relatively simple molecule. It possesses two adjacent nitrogens; however, they differ in reactivity due to the phenyl substituent at $\mathrm{N}-1$. In the literature there are some reports of alkylations and carboxyalkylations of arylhydrazines, which show the differing reactivities of the two nitrogens. Alkylations using alkylhalides such as benzylbromide or methyliodide preferably occur at $\mathrm{N}-1$ if the alkylhalide is not overly bulky. ${ }^{5}$ Over alkylation, to produce the ammonium salts, is observed if the hydrazine is not activated by a strongirreversible base such as sodium metal or butyl lithium. ${ }^{6}$ Reductive amination, via hydrazones, has been used to selectively alkylate at $\mathrm{N}-2$ using ketones or aldehydes and reductant. ${ }^{7}$ On the other hand, a few 3-arylcarbazates, or alkyl 2-arylhydrazinecarboxylates, have been synthesized in moderate yields with use of chloroalkylformates or BOC-anhydride. ${ }^{8}$

(2) Pearson, R. G. J. Am. Chem. Soc. 1963, 85, 3533-3539. Pearson, R. G.; Songstad, J. J. Am. Chem. Soc. 1967, 89, 1827-1836.

(3) Tundo, P.; Selva, M.; Perosa, A.; Memoli, S. J. Org. Chem. 2002 67, 1071-1077. Tundo, P.; Selva, M.; Bomben, A. Org. Synth. 2004, 76, 640 .

(4) Tundo, P.; Bressanello, S.; Loris, A.; Sathicq, G. Pure Appl. Chem. 2005, 77, 1719-1725.

(5) Smith, P. A. S.; DeWall, G. L. J. Am. Chem. Soc. 1977, 99, 57515760.

(6) Audrieth, L. F.; Weisiger, J. R.; Carter, H. E. J. Org. Chem. 1941, 6, 417-420. West, R.; Stewart, F. J. Am. Chem. Soc. 1970, 92, 853-859.

(7) Abdel-Magid, A. F.; Carson, K. G.; Harris, B. D.; Maryanoff, C. A.; Shah, R. D. J. Org. Chem. 1996, 61, 3849-3862. Goodwin, R. C.; Bailey, J. R. J. Am. Chem. Soc. 1927, 49, 219-227.

(8) Huang, P.-K. C.; Kosower, E. M. J. Am. Chem. Soc. 1968, 90, 23542362. Kisselijova, K.; Bhatia, P. A.; Brooks, C. D. W.; Basha, A.; Ratajczyk, J. D.; Gunn, B. P.; Bouska, J. B.; Lanni, C.; Young, P. R.; Bell, R. L. Carter, G. W. J. Med. Chem. 1996, 39; 3938-3950. Tšubrik, O.; Sillard, R.; Mäeorg, S.; Mäeorg, U. Org. Lett. 2006, 8, 43-45. 
SCHEME 1. Methylation of Phenylacetonitrile

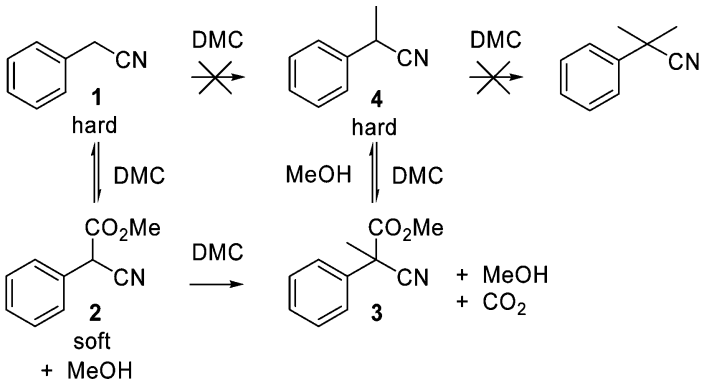

SCHEME 2. Proposed Mechanistic Pathway for the Reaction of Phenylhydrazine and DMC, Using a Brönsted Base

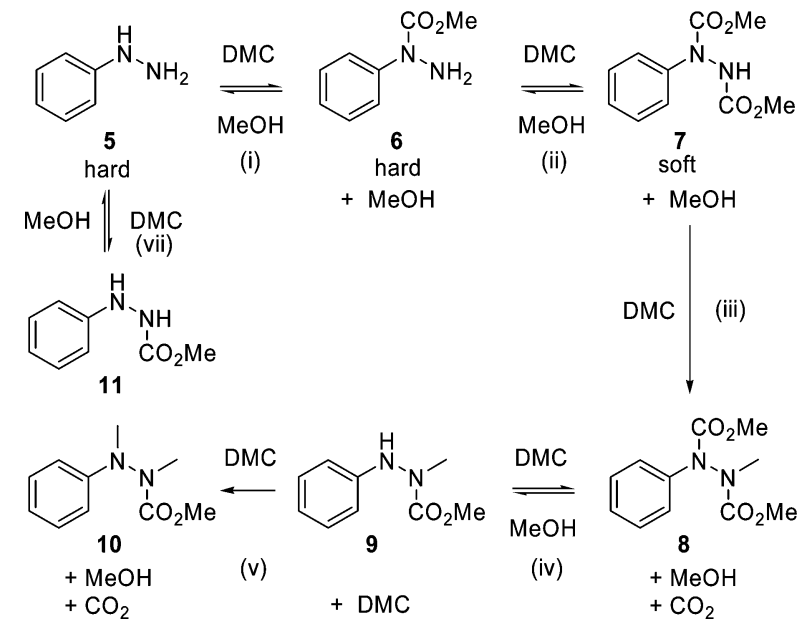

This paper reports the reactivity of the ambident nucleophile, phenylhydrazine, toward the ambident electrophile, DMC, under different conditions to possibly achieve selective reactions at either or both of the nucleophilic centers and to explore the HSAB nature of the nucleophile.

To effect carboxymethylation of phenylhydrazine similar conditions to those that have been used previously for amino nucleophiles were implemented with DMC also used as a solvent. ${ }^{4}$ Base catalysts such as potassium tert-butoxide, sodium methoxide, and cesium carbonate effected carboxymethylation of the phenyl-substituted nitrogen to produce 6 (Scheme 2, i), albeit at different rates and selectivity. The rate of the reactions proceeded in order of base strength, i.e., KO- $t$ - $\mathrm{Bu}>\mathrm{NaOMe}$ $>\mathrm{Cs}_{2} \mathrm{CO}_{3}>\mathrm{K}_{2} \mathrm{CO}_{3}$ (no reaction). In fact, when potassium tertbutoxide was used at room temperature selective carboxymethylation (85\%) was observed. It was only under these conditions that the carbazate $\mathbf{6}$ could be selectively produced and isolated.

When reactions were conducted at reflux $\left(90^{\circ} \mathrm{C}\right)$, subsequent reactions took place. First, carboxymethylation of carbazate 6 at N-2 to produce 7 occurred (Scheme 2, ii), followed by methylation (of 7) to produce $\mathbf{8}$ (Scheme 2, iii). Although significant quantities of each compound could be found during the reactions, large conversions of phenylhydrazine with great selectivity for either product were not achieved under normal reflux conditions. Carbazate $\mathbf{7}$ was converted into carbazate $\mathbf{8}$; however, this was accompanied by further reactions that produced carbazates 9 and 10. Usually, mixtures containing mainly 8 and 9 were obtained when $\mathrm{KO}-t$-Bu or $\mathrm{NaOMe}$ was used; however, reactions with $\mathrm{Cs}_{2} \mathrm{CO}_{3}$ progressed more slowly

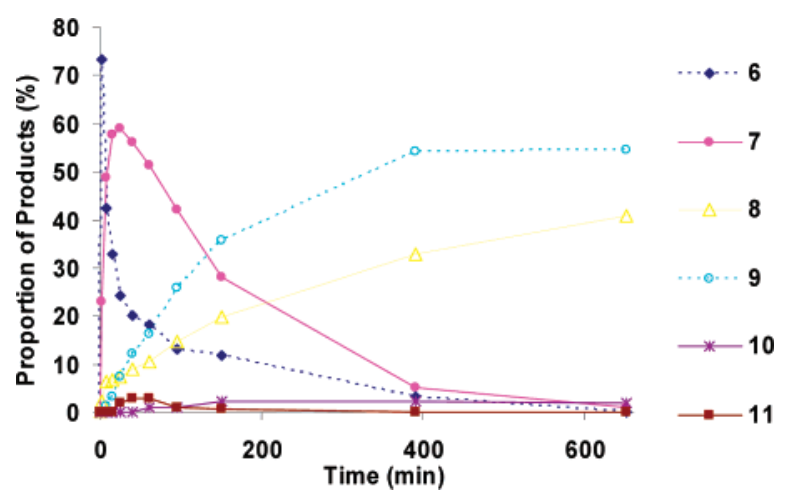

FIGURE 1. Reaction of phenylhydrazine, 3 equiv of $\mathrm{NaOMe}$, and $\mathrm{DMC}$ at Reflux $\left(90^{\circ} \mathrm{C}\right)$.

SCHEME 3. Formation of Carbazate 9

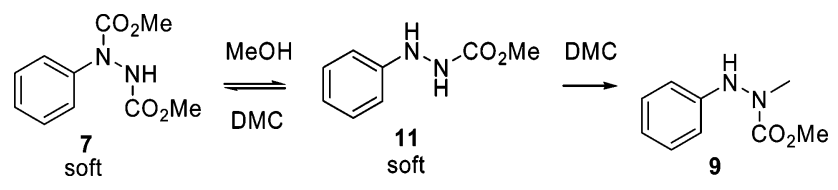

producing compounds $\mathbf{6}$ and $\mathbf{9}$ as the major components (Figure 1 and Supporting Information).

A possible reaction pathway for these products is given in Scheme 2. An important process in this reaction is the methanolysis of $\mathbf{8}$ to produce $\mathbf{9}$ (Scheme 2, iv). Methanol is produced in the reaction when either carboxymethylation or methylation occurs. Therefore, the control of the amount of $\mathrm{MeOH}$ in the reaction can be important for product selectivity. In fact, phenylhydrazine (5) was reacted with DMC and KO$t$-Bu with the removal of methanol (5 $\AA$ molecular sieves) to produce carbazate $\mathbf{8}$ in high selectivity $(>90 \%)$ via carbazates 6 and 7. The removal of methanol from the reaction reduces methanolyis, although some of carbazate $\mathbf{1 0}(<10 \%)$ was still produced.

On the other hand, excess methanol was utilized to promote the methanolysis. Optimum conditions were found when methanol was added (with base) after the formation of compounds $\mathbf{8}$ and $\mathbf{9}$ in reactions with DMC as the only initial solvent. Selectivity higher than $90 \%$ was achieved for carbazate 9 by using this method. In another procedure where methanol was added at the beginning, more complex mixtures were produced. A considerable amount of methyl 3-phenylcarbazate 11, possibly a product of methanolysis of carbazate 7, was observed. Methanolysis of both $\mathbf{7}$ and $\mathbf{8}$ with methanol (Schemes 3 and 2 , iv) presumably occurs more favorably at the phenylsubstituted nitrogen because there is a greater stabilization of the hydrazine leaving group and also there is a greater release of steric strain at this nitrogen possessing bulkier susbstituents.

Although carbazate $\mathbf{1 1}$ was produced in decent quantities with both DMC and $\mathrm{MeOH}$, the method would not be suitable for the preparative synthesis of such methyl 3-arylcarbazates due to the degree of coproduct formation. Although it was not our main aim, we report preliminary results for the preparative synthesis of methyl 3-phenylcarbazate (11) using classical metal catalysts.

$\mathrm{Pb}(\mathrm{OAc})_{2}$ and $\mathrm{Sn}\left[\mathrm{O}_{2} \mathrm{CCH}(\mathrm{Et}) \mathrm{Bu}\right]_{2}$ in the absence of base were successful in producing carbazate $\mathbf{1 1}$ selectively with complete conversion of the phenylhydrazine. With these catalysts activation of the primary nitrogen, N-2, rather than the secondary anilino nitrogen, $\mathrm{N}-1$, was observed. Also methylation was not 
TABLE 1. Synthesis of Carboxymethylated Hydrazines from Phenylhydrazine

\begin{tabular}{|c|c|c|c|c|c|c|c|}
\hline entry & product & base/catalyst & equiv of base & conditions & time & yield $(\%)$ & comment \\
\hline 1 & 6 & $\mathrm{KO}-t-\mathrm{Bu}$ & 1 & Rt & $25 \mathrm{~min}$ & $85^{a}$ & \\
\hline 2 & 8 & $\mathrm{KO}-t-\mathrm{Bu}$ & 1 & reflux, removal of $\mathrm{MeOH}$ & $3 \mathrm{~h} 10 \mathrm{~min}$ & $95^{a}$ & \\
\hline 3 & 9 & $\mathrm{NaOMe}$ & 4 & $\begin{array}{l}\text { reflux, } 3 \text { equiv of } \mathrm{NaOMe} \\
1 \text { equiv of } \mathrm{NaOMe} \text { and } \mathrm{MeOH} \text {, reflux }\end{array}$ & $\begin{array}{l}5 \mathrm{~h} 40 \mathrm{~min} \\
3 \mathrm{~h} 30 \mathrm{~min}\end{array}$ & $79^{a}$ & $>90 \%$ purity $^{b}$ \\
\hline 4 & 11 & $\mathrm{~Pb}(\mathrm{OAc})_{2}$ & 1 & reflux & $18 \mathrm{~h}$ & $\begin{array}{l}89^{b} \\
76^{a}\end{array}$ & $>95 \%$ purity $^{b}$ \\
\hline 5 & 11 & $\mathrm{~Pb}(\mathrm{OAc})_{2}$ & 0.2 & reflux & $20 \mathrm{~h}$ & $\begin{array}{l}88^{b} \\
70^{a}\end{array}$ & $>95 \%$ purity $^{b}$ \\
\hline 6 & 11 & $\mathrm{Sn}\left[\mathrm{O}_{2} \mathrm{CCH}(\mathrm{Et}) \mathrm{Bu}\right]_{2}$ & 0.2 & reflux & 25 h 45 min & $58^{a}$ & \\
\hline 7 & 11 & $\mathrm{Ti}(\mathrm{O}-t-\mathrm{Bu})_{4}$ & 1 & reflux & $51 \mathrm{~h}$ & $36^{a}$ & $80 \%$ of $11 ; 20 \%$ of $\mathbf{6}^{b}$ \\
\hline $8^{c}$ & 10 & $\mathrm{KO}-t-\mathrm{Bu}$ & 5 & $\begin{array}{l}\text { reflux, } 2 \text { equiv of base added at } \\
0 \text { and } 3 \mathrm{~h} \text { and } 1 \text { equiv at } 32.5 \mathrm{~h}\end{array}$ & $35 \mathrm{~h}$ & $65^{a}$ & \\
\hline
\end{tabular}

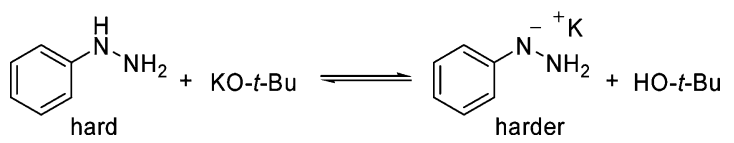

FIGURE 2. Acid-base equilibrium of phenylhydrazine and potassium butoxide.

observed. When $\mathrm{Ti}(\mathrm{O}-\mathrm{t}-\mathrm{Bu})_{4}$ was used, the reaction took considerably more time and the selectivity toward carbazate $\mathbf{1 1}$ over carbazate $\mathbf{6}$ was $80 \%$ after complete conversion of phenylhydrazine (Table 1, entry 7). In either case, apparently these metal complexes activated phenylhydrazine for attack as a hard nucleophile, more prominently at $\mathrm{N}-2$, which is different from the activation by a Brönsted base.

The HSAB theory can be adequately used to interpret the reaction when using a strong base. As observed with primary amines and anilines, ${ }^{4}$ phenylhydrazine reacts in a similar manner; however, in this case there is the equivalent of both a primary and a secondary amine. When $\mathrm{KO}-t$ - $\mathrm{Bu}$ is used, there are two likely explanations for the initial key reaction, which produces 6 (Scheme 2, step i). Either the base weakens the $\mathrm{N}-\mathrm{H}$ bond of $\mathrm{N}-1$ via coordination to the proton increasing the nucleophilicity of $\mathrm{N}-1$ or deprotonation of N-1 occurs, which produces the phenylhydrazinide anion (Figure 2). The latter is likely, because the $\mathrm{p} K_{\mathrm{a}}$ of phenylhydrazine $(\mathrm{N}-1), 28.8$, is lower than that of tert-butanol, 32.2. ${ }^{9}$

Therefore, the anion of phenylhydrazine, a harder nucleophile and much more reactive than the Lewis basic $\mathrm{NH}$ and $\mathrm{NH}_{2}$, attacks the hard carbon of DMC to form carbazate 6. Similar activation of phenylhydrazine with strong bases has been utilized previously in alkylations of phenylhydrazines with equivalent chemoselectivity. ${ }^{6}$ In the case of $\mathrm{NaOMe}$ and $\mathrm{Cs}_{2} \mathrm{CO}_{3}$, which are weaker bases, carboxymethylation is made possible at reflux temperature $\left(90^{\circ} \mathrm{C}\right)$.

In the following step (Scheme 2, ii), carboxymethylation occurs at $\mathrm{N}-2$. It is possible that this reaction occurs via a similar mechanism as the previous reaction (Scheme 2, step i). For this mechanism to occur the $\mathrm{p} K_{\mathrm{a}}$ of the $\mathrm{N}-2$ would have to be significantly lower than that at $\mathrm{N}-2$ of the parent hydrazine $\mathbf{5}$. Although the carboxymethyl moiety is not directly attached to $\mathrm{N}-2$ its presence may still assist in reducing the $\mathrm{p} K_{\mathrm{a}}$ of the $\mathrm{N}-2$

(9) Olmstead, W. N.; Margolin, Z.; Bordwell, F. G. J. Org. Chem. 1980 , 45, 3295-3299. Zhao, Y.; Bordwell, F. G.; Cheng, J.-P.; Wang, D. J. Am Chem. Soc. 1997, 119, 9125-9129.

\section{SCHEME 4. Reaction of 1-Methyl-1-phenylhydrazine with} DMC, Using a Brönsted Base

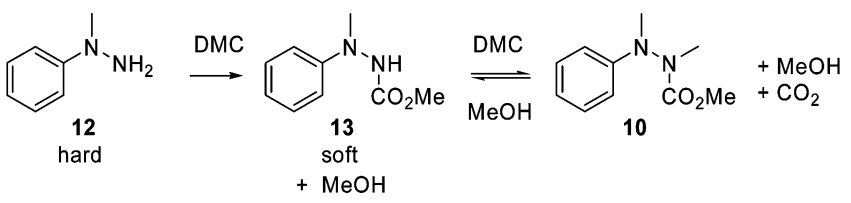

hydrogens, ${ }^{10}$ or/and a general basic catalysis occurs (see ref 4 for comparison).

Results from reactions with 1-methyl-1-phenylhydrazine (12) (Table 1, entry 8 and Scheme 4) demonstrate the importance of the substituents at $\mathrm{N}-1$. In this case an electron-donating substituent is present, which results in the deactivation of $\mathrm{N}-2$ of the hydrazine in this reaction, presumably increasing the $\mathrm{p} K_{\mathrm{a}}$ of $\mathrm{N}-2$. Only when $\mathrm{KO}-t$-Bu, the stronger base, was used was significant conversion of 1-methyl-1-phenylhydrazine (12) observed. However, even in this case 5 equiv were required to effect full conversion of the hydrazine because the methanol produced from the reaction buffers the system, therefore reducing the base strength in the reaction.

Once 7 is produced, N-2 is rendered a soft nucleophile due to its ability to delocalise its electrons across the carbonyl moiety. Similar to primary amines and anilines, $\mathrm{N}-2$ of carbazate $\mathbf{7}$ is subsequently methylated (Scheme 2, iii) to produce $\mathbf{8}$. After methylation, both nitrogens are fully substituted, and as discussed before methanolysis at the $\mathrm{N}-1$ occurs producing carbazate 9.

Carbazate 9, bearing an $\mathrm{N}-\mathrm{H}$, is able to react with DMC once again. The reaction of isolated carbazate 9 with KO- $t$-Bu in refluxing DMC produced both carbazate $\mathbf{1 0}(36 \%)$ and compound $8(46 \%)$ after $2 \mathrm{~h}$, suggesting that N-1 of carbazate 9 possesses both hard and soft nucleophilic nature. The difference in nucleophilicity from that of the same nitrogen of phenylhydrazine is most likely due to the substitutents of N-2. Carbazate 9 possesses a carboxymethyl group at N-2, which can affect the electron density of $\mathrm{N}-1$, similar to the effect discussed previously. Therefore, with both an adjacent phenyl ring and neighboring carbamate moiety, this carbazate can allow for more stabilization of $\mathrm{N}-1$ nonbonding electrons, giving the borderline nucleophilicity.

In conclusion, under basic conditions phenylhydrazine, and its products, reacted with DMC in accordance with the HSAB theory. It was also shown that the reactivity of both nitrogens

(10) With some hydrazines, the $\mathrm{p} K_{\mathrm{a}}$ of $\mathrm{N}-2$ is lower in comparison to the parent hydrazine if there is an electron-withdrawing group present on the adjacent nitrogen, ref 9 . 
is affected by the susbstituents of the other and subtle changes to the HSAB nucleophilicity were observed. Such results show that many compounds can be selectively produced with ambident nucleophiles under different conditions showing the versatile nature of $\mathrm{DMC}$.

\section{Experimental Section}

Synthesis of Methyl 2-phenylcarbazate (6). To a stirring solution of phenylhydrazine $(0.400 \mathrm{~g}, 3.70 \mathrm{mmol})$ and dimethyl carbonate (13.33 g, $0.148 \mathrm{~mol})$ was added KO- $t$-Bu (0.415 g, 3.70 $\mathrm{mmol}$ ) and the mixture was left to react for $25 \mathrm{~min}$ at rt. After this time, $\mathrm{Et}_{2} \mathrm{O}(40 \mathrm{~mL})$ was added to the reaction mixture and the resulting suspension was poured onto silica gel, then filtered through a silica plug and washed with ether. The volatile components of the filtrate were removed in vacuo to afford an orange oil, which was crystallized with ether $(0.524 \mathrm{~g}, 85 \%), \mathrm{mp} 71.5-73.0^{\circ} \mathrm{C} .{ }^{1} \mathrm{H}$ NMR $\left(300 \mathrm{MHz}, \mathrm{CDCl}_{3}\right) \delta 3.75(\mathrm{~s}, 3 \mathrm{H}), 4.52(\mathrm{~s}, 2 \mathrm{H}$ (disappeared with $\left.\mathrm{D}_{2} \mathrm{O}\right)$ ), $7.13(\mathrm{t}, J=7.3 \mathrm{~Hz}, 1 \mathrm{H}), 7.31(\mathrm{t}, J=7.2 \mathrm{~Hz}, 2 \mathrm{H})$, $7.43(\mathrm{~d}, J=8.0 \mathrm{~Hz}, 2 \mathrm{H}) .{ }^{13} \mathrm{C}$ NMR $\left(75 \mathrm{MHz}, \mathrm{CDCl}_{3}\right) \delta 53.5$, 123.7, 125.7, 128.5, 142.7, 156.8. Mass spectrum (EI) $\mathrm{m} / \mathrm{z} 166\left(\mathrm{M}^{+}\right.$, 75\%), $107\left(\mathrm{PhN}_{2} \mathrm{H}_{2}{ }^{+}, 100\right), 91(10), 77\left(\mathrm{Ph}^{+}, 95\right)$. HRMS (EI) $\mathrm{m} / \mathrm{z}$ calcd for $\mathrm{C}_{8} \mathrm{H}_{10} \mathrm{~N}_{2} \mathrm{O}_{2}\left(\mathrm{M}^{+\bullet}\right)$ 166.0737, found 166.0737.

Synthesis of Dimethyl 1-Phenyl-2-methylhydrazine-1,2-dicarboxylate (8). Phenylhydrazine $(0.800 \mathrm{~g}, 7.40 \mathrm{mmol})$ and DMC (45 g, $0.50 \mathrm{~mol}$ ) were added to an RBF equipped with a magnetic stirrer bar and a Dean-Stark apparatus containing $5 \AA$ molecular sieves (leaving $14 \mathrm{~mL}$ solvent capacity). The reaction mixture was stirred and heated at reflux. Once refluxing, KO- $t$-Bu (1.00 g, 8.91 mmol) was added to the reaction mixture which was left heating at reflux for $3 \mathrm{~h} 10 \mathrm{~min}$. After this time, the reaction was cooled to room temperature and $\mathrm{Et}_{2} \mathrm{O}(25 \mathrm{~mL})$ was added. The resulting suspension was filtered though silica gel. The volatile components of the filtrate were removed in vacuo to afford a light orange oil (1.67 g, 95\%). ${ }^{1} \mathrm{H}$ NMR (300 MHz, DMSO, 355 K) $\delta 3.07(\mathrm{~s}$, $3 \mathrm{H}), 3.64(\mathrm{~s}, 3 \mathrm{H}), 3.68(\mathrm{~s}, 3 \mathrm{H}), 7.15-7.20(\mathrm{~m}, 1 \mathrm{H}), 7.28-7.35$ (m, 1H). ${ }^{13} \mathrm{C}$ NMR $\left(300 \mathrm{MHz}, d_{6}\right.$-DMSO, $\left.355 \mathrm{~K}\right) \delta 36.5,53.7$, $53.8,123.7,126.6,129.2,140.7,154.3,156.6$. Mass spectrum (EI) $m / z, 238\left(\mathrm{M}^{+}, 53 \%\right), 179\left(\mathrm{PhN}_{2} \mathrm{MeCO}_{2} \mathrm{Me}^{+}, 17\right), 151\left(\mathrm{PhNCO}_{2}-\right.$ Me, 70), 135 (38), 119 (20), 106 (50), 91 (30), $77\left(\mathrm{Ph}^{+}\right), 59$ (35), 43 (35). HRMS (EI) $\mathrm{m} / z$ calcd for $\mathrm{C}_{11} \mathrm{H}_{14} \mathrm{~N}_{2} \mathrm{O}_{4}\left(\mathrm{M}^{+} \bullet\right) 238.0948$, found 238.0915.

Synthesis of Methyl 2-Methyl-2-phenylcarbazate (9). To a stirring solution of phenylhydrazine $(0.400 \mathrm{~g}, 3.70 \mathrm{mmol})$ and dimethyl carbonate $(13.32 \mathrm{~g}, 0.148 \mathrm{~mol})$ was added $\mathrm{NaOMe}(0.600$ $\mathrm{g}, 11.10 \mathrm{mmol}$ ) and the suspension was heated at reflux. After $5 \mathrm{~h}$
$40 \mathrm{~min}$ another equivalent of $\mathrm{NaOMe}(0.200 \mathrm{~g}, 3.70 \mathrm{mmol})$ and $\mathrm{MeOH}$ (4.74 g, $0.148 \mathrm{mmol}$ ) were added and the reaction was refluxed. After $3 \mathrm{~h} 30 \mathrm{~min}$ the reaction was cooled to room temperature followed by pouring the reaction mixture on silica gel suspended in ether and stirring at room temperature for $30 \mathrm{~min}$. After this time the reaction components were washed through the silica gel with ether. The filtrate was evaporated and the solvent removed in vacuo leaving an orange oil. The oil was chromatographed on silica gel using a $1: 1 \mathrm{Et}_{2} \mathrm{O} /$ hexane mixture as the eluent, which yielded the desired product 9 as an orange oil $\left(R_{f} 0.20,0.530\right.$ g, 79\%). ${ }^{1} \mathrm{H}$ NMR $\left(300 \mathrm{MHz}, \mathrm{CDCl}_{3}\right) \delta 3.24(\mathrm{~s}, 3 \mathrm{H}), 3.72(\mathrm{~s}, 3 \mathrm{H})$, 5.97 (br s, 1H), $6.72(\mathrm{~d}, J=7.7 \mathrm{~Hz}, 2 \mathrm{H}), 6.83-6.92(\mathrm{~m}, 1 \mathrm{H}), 7.24$ $(\mathrm{dd}, J=8.5,7.4 \mathrm{~Hz}, 2 \mathrm{H}) .{ }^{13} \mathrm{C} \mathrm{NMR}\left(75 \mathrm{MHz}, \mathrm{CDCl}_{3}\right) \delta 37.5$ (br), 53.3, 112.8, 120.8, 129.3, 147.8, 157.7. Mass spectrum (EI) $\mathrm{m} / \mathrm{z}$ $180\left(\mathrm{M}^{+}, 65 \%\right), 121\left(\mathrm{PhNHNMe}^{+}, 85\right), 92(100), 77\left(\mathrm{Ph}^{+}, 40\right), 65$ (45). HRMS (ESI) $\mathrm{m} / z$ calcd for $\mathrm{C}_{9} \mathrm{H}_{12} \mathrm{~N}_{2} \mathrm{O}_{2}\left(\mathrm{M}^{+\bullet}\right) 180.0893$, found 180.0912 .

Synthesis of Methyl 3-Phenylcarbazate (11). A stirring suspension of phenylhydrazine $(0.800 \mathrm{~g}, 7.40 \mathrm{mmol}), \mathrm{Pb}(\mathrm{OAc})_{2}(2.41 \mathrm{~g}$, $7.40 \mathrm{mmol})$, and dimethyl carbonate $(26.64 \mathrm{~g}, 0.296 \mathrm{~mol})$ was heated at reflux for $18 \mathrm{~h}$. After this time, $\mathrm{Et}_{2} \mathrm{O}(25 \mathrm{~mL})$ was added to the reaction mixture and the resulting suspension was poured onto a silica plug, filtered, and washed with ether. The volatile components of the filtrate were removed in vacuo to afford a light orange solid $(1.10 \mathrm{~g}, 89 \%,>95 \%$ purity GC). The solid was recrystallized with boiling toluene, which yielded a white solid (0.937 g, 76\%), mp 115.5-116.0 ${ }^{\circ} \mathrm{C}$ (lit. ${ }^{8} \mathrm{mp} 110.0-111.0{ }^{\circ} \mathrm{C}$ ). ${ }^{1} \mathrm{H}$ NMR $\left(300 \mathrm{MHz}, \mathrm{CDCl}_{3}\right) \delta 3.77(\mathrm{~s}, 3 \mathrm{H}), 5.77(\mathrm{~s}, 1 \mathrm{H}), 6.56(\mathrm{br}$ $\mathrm{s}, 1 \mathrm{H}), 6.84(\mathrm{~d}, J=8.0 \mathrm{~Hz}, 2 \mathrm{H}), 6.91(\mathrm{t}, J=7.4 \mathrm{~Hz}, 1 \mathrm{H}), 7.25(\mathrm{t}$, $J=7.9 \mathrm{~Hz}, 2 \mathrm{H}) .{ }^{13} \mathrm{C} \mathrm{NMR}\left(75 \mathrm{MHz}, \mathrm{CDCl}_{3}\right) \delta 52.9,113.1,121.1$, 129.3, 147.9, 157.6. Mass spectrum (EI) $\mathrm{m} / \mathrm{z} 166\left(\mathrm{M}^{+}, 73 \%\right), 134$ $\left(\mathrm{PhN}_{2} \mathrm{H}^{+}, 26\right),\left(\mathrm{PhN}_{2} \mathrm{H}_{2}^{+}, 100\right), 91$ (24), $77\left(\mathrm{Ph}^{+}, 71\right)$. HRMS (EI) $\mathrm{m} / \mathrm{z}$ calcd for $\mathrm{C}_{8} \mathrm{H}_{10} \mathrm{~N}_{2} \mathrm{O}_{2}\left(\mathrm{M}^{+\bullet}\right)$ 166.0737, found 166.0751.

Acknowledgment. Contributions from the Consorzio Interuniversitario Nazionale "La Chimica per l'Ambiente", INCA (Interuniversity National Consortium "Chemistry for the Environment"). We also thank both Prof. V. Lucchini and Prof. S. Antoniutti for their assistance with NMR spectroscopy.

Supporting Information Available: Full experimental details, spectral data, and characterization for all new compounds. This material is available free of charge via the Internet at http://pubs. acs.org.

JO701818D 